This is an Accepted Manuscript of the article Serra, T., Soler, M., Pous, N. and Colomer, J. (2019). Daphnia magna filtration, swimming and mortality under ammonium, nitrite, nitrate and phosphate. Science of The Total Environment, vol. 656 (15 March 2019), p. 331-337. Available online at https://doi.org/10.1016/j.scitotenv.2018.11.382

(C)2019. This manuscript version is made available under the CC-BY-NC-ND 4.0 license.

(c) $\underset{\mathrm{BY}}{\mathrm{N}} \mathrm{NC}_{\mathrm{ND}}$ 
1 Daphnia magna filtration, swimming and mortality under ammonium, nitrite, nitrate

\section{2 and phosphate}

3 Teresa Serra ${ }^{1,{ }^{*}}$, Marçal Soler $^{1}$, Narcís Pous $^{2}$ and Jordi Colomer ${ }^{1}$

$4 \quad{ }^{1}$ Department of Physics. University of Girona. 17003-Girona (Spain)

$5 \quad{ }^{2}$ Lequia, Institute of the Environment. University of Girona. 17003-Girona (Spain)

6 *corresponding author's email: teresa. serra@udg.edu

7 Keywords: Daphnia magna, wastewater reuse, Daphnia magna filtration, bio-indicators

\section{Abstract}

9 Biological methods are a promising approach to treating wastewater in order to produce water of an appropriate quality for sub-potable water purposes, thus reducing pressure on potable water sources. Daphnia magna are organisms that filter on small suspended particles and bacteria and so may be able to clarify and disinfect wastewater. However, Daphnia magna are sensitive to common chemicals and might be vulnerable to the quality of the wastewater. This study analyses the filtration, mobility and mortality rates of Daphnia magna exposed to seven days of changing concentrations of ammonium, nitrite, nitrate and phosphate. Inactivation increased with the time of exposure for both

17 nitrite and ammonium, with a 50\% inactivation in Daphnia magna filtrations after 7 days of exposure at nitrite concentrations above $6 \mathrm{ppm}$ and ammonium concentrations above $40 \mathrm{ppm}$. The Daphnia filtration remained unaltered in the nitrate and phosphate concentrations. Mortality increased with nitrite and ammonium concentrations, but not with phosphate or nitrate. The swimming velocity of Daphnia magna individuals decreased when both nitrite and ammonium concentrations increased and also with phosphate concentrations above 30 ppm. However, Daphnia magna swimming velocities remained unaltered in the presence of nitrate concentrations below 100 ppm. 
Introduction

27 Wastewater reuse is an alternative potential water source that might reduce pressure on drinking water resources (Bouzit et al., 2016). Treated wastewater needs to meet established water quality standards to be used for irrigation or urban cleaning, (among other applications (Ait-Mouheb et al., 2018), however, the high capital and operating costs of conventional tertiary treatments can make this unaffordable for some communities. Moreover, most conventional tertiary treatments rely on the use of chemicals, which might also produce some non-desired by-products that could be released into the environment (Jaramillo and Restrepo, 2017). Since water reuse is a promising alternative to using natural water resources in zones where water is scarce, it is important to continue researching alternative low-cost, environmentally-friendly tertiary treatments. One such alternative to explore is the use of natural depuration systems. For instance, filter-feeder organisms such as Daphnia could be used as an alternative method to remove particles found in secondary effluents.

Removing small suspended particles (with diameters below $30 \mu \mathrm{m}$ ) from wastewater poses a challenge because they can go through meshes, filters or settling tanks without

42 being separated from the water phase. Furthermore, as these small particles make the water appear cloudy, this complicates disinfecting it with UV-based technologies. Therefore, it is crucial to find alternative ways to reduce the concentration of these small particles in wastewater. The genus Daphnia is a zooplanktonic population of Cladocera whose ability to disinfect wastewater (Burnet et al., 2017; Serra et al., 2014; Shiny et al.,

47 2005), remove emerging contaminants (Matamoros et al., 2012) and prey on 
wastewater particles with diameters below $30 \mu \mathrm{m}$ (Pau et al., 2013; Serra et al., 2018; Serra and Colomer, 2016) has already been demonstrated. However, Daphnia might be sensitive to some compounds. For this reason they are sometimes used to test water quality (Heger et al., 2018; Van de Perre et al., 2018) because many compounds are toxic for these organisms (Sladkova et al., 2016). Nitrate $\left(\mathrm{NO}_{3}{ }^{-}\right)$concentrations above $56 \mathrm{mgN}^{-N_{3}}{ }_{3}^{-} \mathrm{L}^{-1}\left(250 \mathrm{mgNO}_{3}^{-} \mathrm{L}^{-1}\right)$ together with a water temperature of $26{ }^{\circ} \mathrm{C}$ proved to have lethal effects on a Daphnia population (MacedaVeiga et al., 2015). In addition, ammonia $\left(\mathrm{NH}_{3}\right)$ concentrations over $0.81 \mathrm{mgN}-\mathrm{NH}_{3} \mathrm{~L}^{-1}$ were found to reduce the ingestion rate of E.coli by Daphnia (Norgaard and Roslev, 2016). However, in the same study, Daphnia filtration had already been reduced by $40 \%$

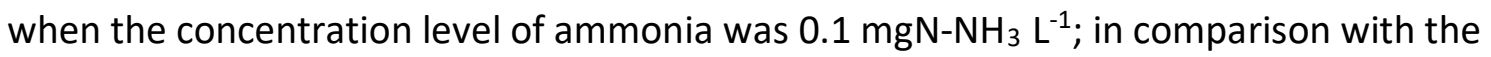
control experiments which had no ammonia. Furthermore, high levels of nitrite in water has been found to have toxic effects on aquatic organisms, producing physiological disturbances (Jensen, 2003). Daphnia obtusa exposed to nitrite concentrations above 2 $\mathrm{mgN}-\mathrm{NO}_{2}{ }^{-} \mathrm{L}^{-1}$ have a reduced survival time compared to the case without nitrite (Xiang et al., 2012). Similar results were obtained after Daphnia similoides were exposed to the same nitrite concentration (Xiang et al., 2011). The presence of clays and cadmium have also been found to reduce the heartbeat of Daphnia (Lari et al., 2017), which would be an indicator of adverse environmental conditions for Daphnia. Low food concentrations have also been found to reduce their heart rate (Lari et al., 2017). Therefore, Daphnia vulnerability makes their application as a tertiary treatment challenging. Even though Daphnia remove small particles, reduce microbial loads and polish nutrients in secondary effluents, their applicability in wastewater treatment plants might be complicated under the presence of some chemical compounds. 
73 It must be noticed that the most common nutrients in wastewater such as ammonium,

74 nitrite, nitrate and phosphate have a great variability during the water treatment in the system, from the inlet to the outlet. For instance, in secondary treatments $\mathrm{N}-\mathrm{NH}_{4}{ }^{+}, \mathrm{N}-$ $\mathrm{NO}_{3}{ }^{-}$and $\mathrm{N}-\mathrm{NO}_{2}{ }^{-}$attain low values of $12 \mathrm{mg} / \mathrm{L}, 0.4 \mathrm{mg} / \mathrm{L}$ and $19 \mathrm{mg} / \mathrm{L}$ in settler effluents and somehow lower in membrane with non-detectable values of $\mathrm{N}-\mathrm{NO}_{2}{ }^{-}$and $\mathrm{N}^{-} \mathrm{NH}_{4}{ }^{+}$ (Paredes et al., 2018). For the same wastewater treatment plant, the inlet presented higher nitrite concentrations with maximum values of $0.9 \mathrm{mg} / \mathrm{L}$. Higher nutrient concentrations can be found at the primary effluent of a wastewater treatment plant with N-NH${ }_{4}^{+}$of $98.2 \mathrm{mg} / \mathrm{L}, \mathrm{P}_{-} \mathrm{PO}_{4}{ }^{3-}$ of $17.3 \mathrm{mg} / \mathrm{L}$ and $\mathrm{N}-\mathrm{NO}_{3}{ }^{-}$of $23.5 \mathrm{mg} / \mathrm{L}$ (Praveen et al., 2018). Other authors state that the total nitrogen and phosphorous in untreated wastewater can range from 20-85 ppm and 4-15 ppm, respectively. However, the effect the most common compounds found in wastewater have on the Daphnia filtration efficiency has scarcely been studied, this study explores the effect the main wastewater compounds found in the tertiary treatment $\left(\mathrm{N}-\mathrm{NH}_{4}{ }^{+}, \mathrm{N}-\mathrm{NO}_{2}{ }^{-}, \mathrm{N}-\mathrm{NO}_{3}{ }^{-}\right.$and $\left.\mathrm{P}-\mathrm{PO}_{4}{ }^{3-}\right)$ have on Daphnia activity. With this information, the applicability of Daphnia magna as an organism for wastewater treatment will be known and in addition, the level at which this system will be suitable (after primary or secondary treatments) will be determined for each type of wastewater and in terms of these contaminants.

92 The toxicity effects biotic and abiotic parameters have on Daphnia magna have been evaluated in terms of their behaviour, that is, filtering rate (Serra et al., 2018), heart beat (Lari et al., 2017), mortality and swimming velocity (Serra et al., 2018; Wickramarathna et al., 2014). Swimming activity has recently received special attention because it is a 
sensitive biomarker that can easily be affected by chemical substances (Bownik, 2017).

97 Therefore, Daphnia mobility is widely used in toxicology tests (Bownik, 2017). In this

98 study the filtering rate, mortality and swimming velocity will be considered in order to analyse the effect of ammonium, nitrite, nitrate and phosphate on Daphnia activity.

Different concentrations of each chemical will be tested separately and will be compared to the experiments without the presence of the contaminants. One expects

that if Daphnia filtration rate and swimming velocity does not differ from that without the contaminant, Daphnia can then be considered effective in removing small particles from wastewater.

\section{Materials and methods}

\section{Daphnia magna characteristics}

The Daphnia magna population was obtained from a laboratory culture kept in a $40 \mathrm{~L}$ container at $20.0 \pm 0.5^{\circ} \mathrm{C}$ and natural daylight photoperiod for one year at the University of Girona. A gentle supply of air ensured the water container was oxygenated and the Daphnia in the container were fed twice a week with a mixture of commercial spirulina powder and Baker's yeast (Saccharomyces cerevisiae). Thirty percent of the water from

113 the container was renewed once a week.

115 For each experiment, Daphnia individuals were collected from the container using a 1.5 $\mathrm{mm}$ mesh in order to be able to discard individuals smaller than $1.5 \mathrm{~mm}$ long. Individuals

117 retained in the mesh larger than $2 \mathrm{~mm}$ were also discarded and returned to the container. Therefore, only 1.5-2.0 mm-long Daphnia individuals were considered for the 
study. Using ImageJ software, the mean size of the Daphnia individuals was analysed from a video recording of 25 individuals and was found to be $1.6 \pm 0.3 \mathrm{~mm}$.

123 Four chemicals were considered for the toxicology analysis: ammonium, nitrite, nitrate and phosphate. The effect each chemical had was tested using a range of concentration

125 levels in align with real levels expected to be encountered in urban wastewater treatment plants (Metcalf\&Eddy et al., 2002). Nitrogen dosages in the form of nitrate

$127\left({\mathrm{~N}-\mathrm{NO}_{3}}^{-}\right)$with concentrations of $0,5,1025,50,75$ and $100 \mathrm{ppm} \mathrm{N}-\mathrm{NO}_{3}{ }^{-}$were obtained from $\mathrm{NaNO}_{3}$. Nitrogen dosages in the form of nitrite $\left(\mathrm{N}-\mathrm{NO}_{2}{ }^{-}\right)$with concentrations of 0 , of ammonium( $\left(\mathrm{N}-\mathrm{NH}_{4}{ }^{+}\right.$) with concentrations of o, 5, 20, 30, 35, 40, 50, 80 and $100 \mathrm{ppm}$ $\mathrm{N}-\mathrm{NH}_{4}{ }^{+}$were obtained from $\mathrm{NH}_{4} \mathrm{Cl}$ and the dosage of phosphorous in the form of phosphate $\left(\mathrm{P}_{-} \mathrm{PO}_{4}{ }^{3-}\right)$ with concentrations of $0,1,5,15,20,30,40$ and 50 ppm $\mathrm{P}^{-} \mathrm{PO}_{4}{ }^{3-}$ were obtained from $\mathrm{NaH}_{2} \mathrm{PO}_{4}$. The concentrations were obtained with a maximum uncertainty of $10 \%$ when considering the error made in the mass of each compound and the volume of water measured.

137 Therefore, the desired concentration of each specific chemical was introduced into a 138 beaker which had been filled with $950 \mathrm{~mL}$ of mineral water (chemical composition: total dissolved solids $=206 \mathrm{mg} / \mathrm{L}$, bicarbonate $\left(\mathrm{HCO}_{3}{ }^{-}\right)=165 \mathrm{mg} / \mathrm{L}$, sulfates $\left(\mathrm{SO}_{4}{ }^{2-}\right)=3.7 \mathrm{mg} / \mathrm{L}$, 140 chloride $\left(\mathrm{Cl}^{-}\right)=18.8 \mathrm{mg} / \mathrm{l}$, calcium $\left(\mathrm{Ca}^{2+}\right)=78 \mathrm{mg} / \mathrm{L}$, magnesium $\left(\mathrm{Mg}^{2+}\right)=16.5 \mathrm{mg} / \mathrm{L}$, sodium $141\left(\mathrm{Na}^{+}\right)=8.3 \mathrm{mg} / \mathrm{L}$ and silica $\left.\left(\mathrm{SiO}_{2}\right)=27.1 \mathrm{mg} / \mathrm{L}\right)$ and $50 \mathrm{~mL}$ of spirulina suspension. The 142 spirulina suspension had been prepared by diluting $1 \mathrm{~g}$ of spirulina powder in $1 \mathrm{~L}$ of 
143 mineral water, which was then mixed for $30 \mathrm{~s}$ at $120 \mathrm{rpm}$ and left for $1 \mathrm{~h}$ so that large

144 spirulina particles would settle. The supernatant was used as the spirulina suspension

145 for the experiments. After introducing the spirulina suspension into the beaker, 50

146 Daphnia individuals were collected from the laboratory culture and gently introduced

147 into the experiments, thus obtaining a final Daphnia concentration of 50 ind $\mathrm{L}^{-1}$. Three

148 replicates for each chemical concentration were carried out. All the experiments were

149 carried out employing the same laboratory light conditions and temperature $\left(20^{\circ} \mathrm{C}\right)$ as

150 the initial laboratory Daphnia culture were used to, in order to avoid any external effects

151 on their behaviour. Control experiments without Daphnia and control experiments

152 without chemicals were also carried out to account for the removal of spirulina due to 153 sedimentation.

\section{Daphnia magna filtration capacity}

156 The spirulina particle size distribution in each beaker was measured with the Lisst-100x

157 particle size analyser (Sequoia Inc.). The Lisst-100x consists of a laser beam and an array

158 of detector rings of progressive diameters which allow the light received at the 159 scattering angles of the beam to be analysed. The device measures particle volume 160 concentrations for 32 size-classes, (logarithmically distributed in the size range of 2.5$161500 \mu \mathrm{m})$, using a procedure based on the diffraction theory of light. The Lisst-100x has 162 been found to perform well when determining particle size distribution and concentration for both organic (Serra et al., 2001) and inorganic particles (Serra et al.,

$1642002 b, 2002 a$ ) in water suspension. Since Daphnia feed on particles less than $30 \mu \mathrm{m}$ in 165 diameter, the volume concentration of particles within the range of 2.5 to $30 \mu \mathrm{m}$ was 166 calculated and used as a proxy to evaluate particle removal. Cladocera are known to 
ingest organic particles when their size overlaps the sizes of the organic particles they feed on (Arruda et al., 1983; Gliwicz, 1990).

169 Since the decrease in particle concentration is expected to be exponential (Pau et al., 2013; Serra and Colomer, 2016), the characteristic time $t$ at which $c / c_{0}$ decreased in $\mathrm{e}^{-}$

$171{ }^{1}=0.37$ was considered as the characteristic time for all the experiments. This time was approximately $4 \mathrm{~h}$ of treatment. Therefore, $\mathrm{c} / \mathrm{c}_{0}$ was calculated in all the experiments. From this ratio, the filtration rate could be determined afterwards. The tests lasted for one week. Daphnia filtration measurements were carried out on four of the seven days (days 1, 2, 4 and 7) that the experiment lasted to estimate the evolution of Daphnia

176 filtration under each chemical dosage. On each measurement day, the water was

177 renewed with the same initial chemical dosage and spirulina concentration and filtration

178 rates were determined. For this purpose, a new set of beakers with the same chemical 179 dosages and the same initial spirulina concentrations were prepared. Daphnia 180 individuals were collected with a mesh from the old beaker to the new one.

181 Daphnia mortality was also determined by counting the number of dead Daphnia on days 2, 4 and 7 for each chemical dosage. The results obtained for Daphnia mortality and Daphnia filtration rates are the mean of the results obtained from the three replicates carried out for each chemical dosage.

The velocity of Daphnia individuals was analysed by videotaping their movements. The camera recorded 25 frames per second and, for each case, the Daphnia trails were recorded for 1 minute, thus resulting in a total of 1,500 frames. These frames were analysed with ImageJ software using the mTrack plug-in following Maison et al. (2012) 

value for the velocities was obtained with the software. For the analysis, only some of

192 the chemical dosages were considered. The trails were recorded on days 2, 4 and 7.

\section{Calculating Daphnia filtration without chemicals}

194 The temporal evolution of the suspended particle concentration can be described through a first order equation with time $t$ and a decay constant $k$ from which the Daphnia magna filtration (F) can be determined (see supplementary material for a complete derivation of the equations).

The Daphnia filtration inactivation (INACT) at a certain chemical concentration $\mathrm{c}_{\mathrm{x}}$ was estimated as,

$$
I N A C T=\log \left(\frac{F(0)}{F\left(c_{x}\right)}\right)
$$

201 Where $F(0)$ is the Daphnia filtration without chemicals and $F\left(c_{x}\right)$ is the Daphnia filtration with the presence of a concentration $\mathrm{c}_{\mathrm{x}}$ the chemical $\mathrm{x}$ studied $\left(\mathrm{x}=\mathrm{NH}_{4}{ }^{+}, \mathrm{NO}_{2}{ }^{-}, \mathrm{NO}_{3}{ }^{-}\right.$or $\left.\mathrm{PO}_{4}{ }^{3-}\right)$. Therefore, cases with lower Daphnia filtration rates under a certain concentration of a chemical compared to filtrations without chemical $\left(F\left(c_{x}\right)<F(0)\right)$, would result in inactivation values (INACT) greater than 1 . In such conditions, the presence of a chemical incapacitates Daphnia filtration. In contrast, cases with INACT=0 mean that the presence of the chemical does not produce any effect on Daphnia filtration and 208 therefore $F\left(c_{x}\right)=F(0)$.

\section{Results}

210 The ratio between the suspended spirulina concentration measured at $t=4 \mathrm{~h}$ and the spirulina concentration obtained at $\mathrm{t}=\mathrm{Oh}$ was plotted versus the chemical dosage for 
212 each chemical concentration tested and for the measurement days i.e., days 1, 2, 4 and

2137 (Figure 1). The ratio $c / c_{0}$ measured during the first four hours of exposure to the 214 chemical on day 1 remains nearly constant with the chemical dosage for all the 215 chemicals tested. However, $c / c_{0}$ increases with the chemical dosage for both $\mathrm{NH}_{4}{ }^{+}$ 216 (Figure $1 \mathrm{a}$ ) and $\mathrm{NO}_{2}^{-}$(Figure $2 \mathrm{~b}$ ) on day 2 of exposure and also increases with the time 217 of exposure from days 2 to 7 at each chemical dosage. At $\mathrm{C}_{\mathrm{NH} 4+}=40 \mathrm{mgN}-\mathrm{NH}_{4}{ }^{+} \mathrm{L}^{-1}$ and 218 after 7 days of exposure, $c / c_{0}$ reaches the $c / c_{0}$ obtained for the control experiment 219 without Daphnia (Figure 1a). For the $\mathrm{NO}_{2}^{-}$tests, at $\mathrm{C}_{\mathrm{NO} 2}=10 \mathrm{mgN}-\mathrm{NO}_{2}^{-} \mathrm{L}^{-1}$ and on day 7 , $220 \mathrm{c} / \mathrm{c}_{0}$ attains the $\mathrm{c} / \mathrm{c}_{0}$ for the control experiment without Daphnia (Figure $1 \mathrm{~b}$ ). The ratio $221 \mathrm{c} / \mathrm{c}_{0}$ does not present any variation at all, i.e., neither with the chemical dosage nor with 222 time of exposure to the chemicals $\mathrm{NO}_{3}{ }^{-}$and $\mathrm{PO}_{4}{ }^{3-}$ (Figures $1 \mathrm{c}$ and $1 \mathrm{~d}$, respectively), and 223 remains at the same ratio as the control experiment without chemicals. 


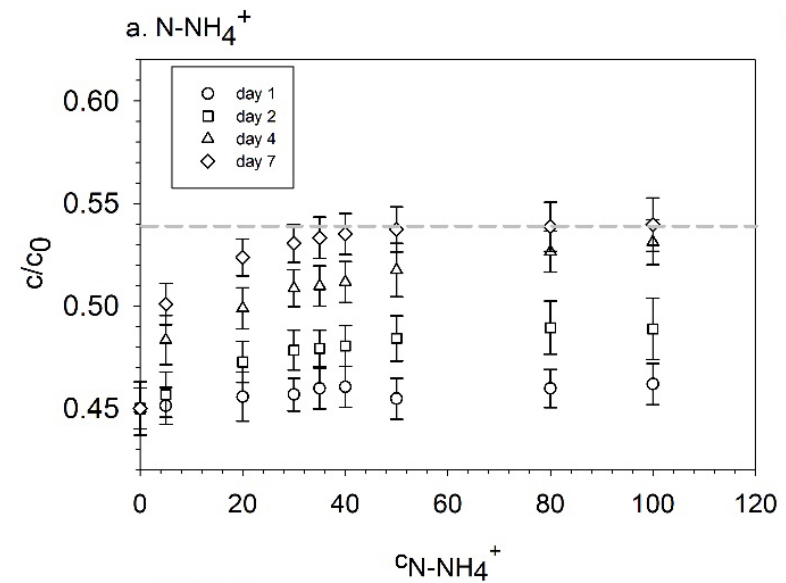

b. $\mathrm{N}-\mathrm{NO}_{2}{ }^{-}$
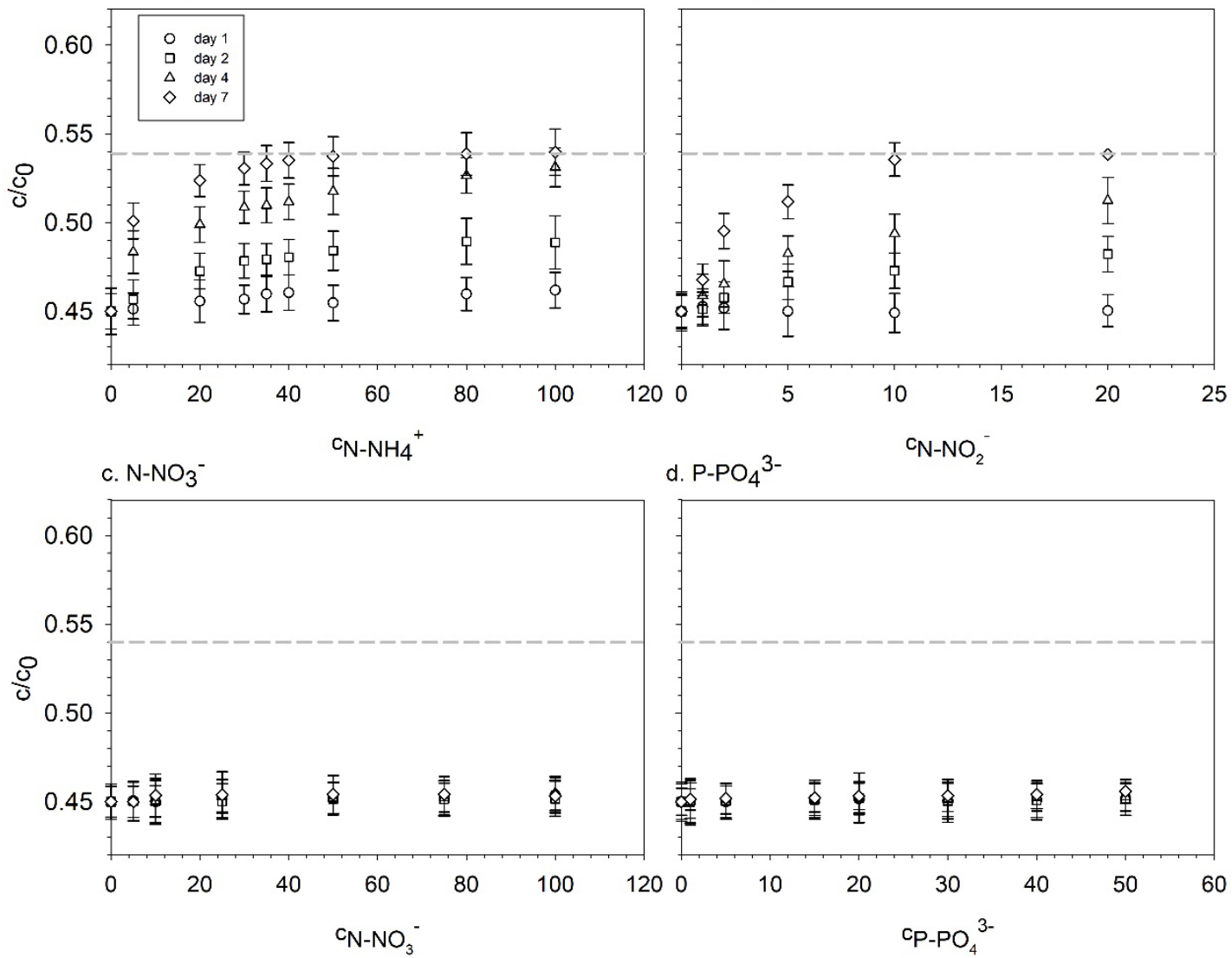

225 Figure 1. Ratio $\mathrm{c} / \mathrm{c}_{0}$ versus the chemical dosage ( $\mathrm{c}$ in $\mathrm{ppm}$ ) and with exposure time for 226 the experiments with $\mathrm{N}-\mathrm{NH}_{4}{ }^{+}$(a), $\mathrm{N}^{-\mathrm{NO}_{2}}{ }^{-}$(b), $\mathrm{N}-\mathrm{NO}_{3}{ }^{-}$(c) and $\mathrm{P}_{-}-\mathrm{PO}_{4}{ }^{3-}$ (d). The horizontal 227 dashed line represents the ratio $c / c_{0}$ for the control experiments without Daphnia.

228 The ratio between $c / c_{0}$ for the experiments with ammonium to that of $c / c_{0}$ in the 229 absence of ammonium has been calculated and it is expected to follow a power function 230 of the chemical concentration ( $\mathrm{C}_{\mathrm{N}-\mathrm{NH} 4+}$, Figure 1$)$ as,

$$
\frac{\left(\frac{c}{c_{0}}\right)_{\text {with chemical }}}{\left(\frac{c}{c_{0}}\right)_{\text {without chemical }}}=\frac{e^{-k} \text { Chem }^{t}}{e^{-k t}}=e^{k^{\prime} t}=a c_{N-N H 4+}^{b}
$$

232 where $a=1$ is a constantand the exponent $b$ will vary with the exposure time $T_{\text {exp }}$ through 
a power function of the time as

$$
b=e T_{e x p}^{d}
$$

235 From equations (13) and (14), $\mathrm{k}^{\prime}$ can be solved as a function of both the chemical concentration $\mathrm{C}_{\mathrm{N}-\mathrm{NH} 4}$ and the exposure time $\mathrm{T}_{\text {exp }}$, resulting in:

$$
k^{\prime}=\frac{e T_{e x p}^{d}}{t} \ln \left(c_{N-N H 4+}\right)
$$

where e and d are constants that will depend on the chemical. For the case of $\mathrm{N}^{-\mathrm{NH}_{4}}{ }^{+}$, $e=0.003$ and $d=0.540$. Therefore, it is possible to write

$$
T_{e x p}=\left(\frac{k \prime t}{e \ln c_{N-N H 4+}}\right)^{1 / d}
$$

241 Considering a case where the ratio $\left(c / c_{0}\right)_{\text {with chemical }} /\left(c / c_{0}\right)_{\text {without chemical }}=1.20$, i.e., the

$242\left(c / c_{0}\right)_{\text {with chemicals }}$ is $20 \%$ greater than $\left(c / c_{0}\right)_{\text {without chemicals, }} k^{\prime}=\ln (1.20) / t$ (from equation

243 13), where $t=4 h$. This $20 \%$ increase in $c / c_{0}$ corresponds to $c / c_{0}=0.54$ of spirulina, which

244 is equal to that obtained only by sedimentation, i.e., no spirulina particles were

245 ingested by Daphnia. In such case, the values of $c_{x}{ }^{\max }, T_{\exp }{ }^{\max }$ that inhibit completely 246 the Daphnia filtration will follow:

$$
T_{\text {exp }}^{\max }=\left(\frac{\ln 1.20}{e \ln c_{N-N H 4+}}\right)
$$

248 Therefore, the conditions $\left(\mathrm{C}_{\mathrm{N}-\mathrm{NH} 4+}{ }^{\max }, \mathrm{T}_{\exp }{ }^{\max }\right)$ that fall above the curved line in Figure 2

249 will inhibit Daphnia filtration. The same calculation was carried out for the experiments 250 with nitrite, where $e=0.008$ and $d=0.385$. For the case of ammonium and nitrite $T_{\exp } \max$ versus $c_{x}{ }^{\max }$ are presented in Figure 2. For $c_{x}{ }^{\max }$ below $14 \mathrm{ppm}$ of contaminant, the

252 maximum exposure time for ammonium falls below that of nitrite, indicating that 
253 ammonium has a greater effect on Daphnia ingestion. However, for concentrations

254 above $14 \mathrm{ppm}$, nitrite has a greater effect than ammonium on Daphnia ingestion. These

255 results might indicate which of these contaminants limit the Daphnia filtration.

256 However, more experiments should be done to exactly assess whether a combination

257 of these chemicals would enhance the inhibition effect of Daphnia filtration compared 258 with the experiments here presented.

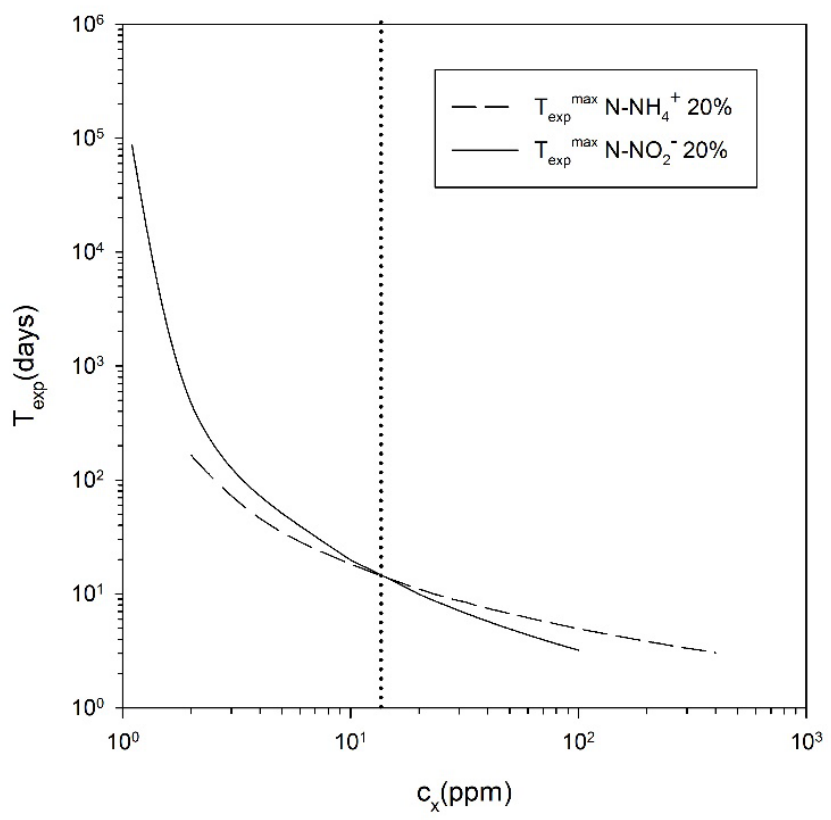

259

260 Figure 2. $\mathrm{T}_{\text {exp }}{ }^{\max }$ (in days) versus $\mathrm{C}_{\mathrm{x}}{ }^{\max }$ (in ppm) for both ammonium $\left(\mathrm{N}^{-\mathrm{NH}_{4}}{ }^{+}\right.$) and nitrite $261\left(\mathrm{~N}-\mathrm{NO}_{2}{ }^{-}\right)$.

263 The inactivation (INACT) for each concentration and with time was calculated from

264 equation 12 and plotted in Figure 4. INACT increased with the chemical dosage and with

265 the exposure time for both $\mathrm{N}^{-\mathrm{NH}_{4}}{ }^{+}$and $\mathrm{N}^{-\mathrm{NO}_{2}}{ }^{-}$(Figures $3 a$ and $3 \mathrm{~b}$ ). For these cases, 
INACT was above 0 during the first day of exposure and was above 1 in the second day.

267 For the chemicals $\mathrm{N}-\mathrm{NO}_{3}{ }^{-}$and $\mathrm{P}_{-}-\mathrm{PO}_{4}{ }^{3-}$, the inactivation was 0 , in accordance with the 268 fact that $c / c_{0}$ remained unaltered with the presence of these chemicals and with the 269 time of exposure (Figure $1 \mathrm{c}$ and $1 \mathrm{~d}$, respectively).
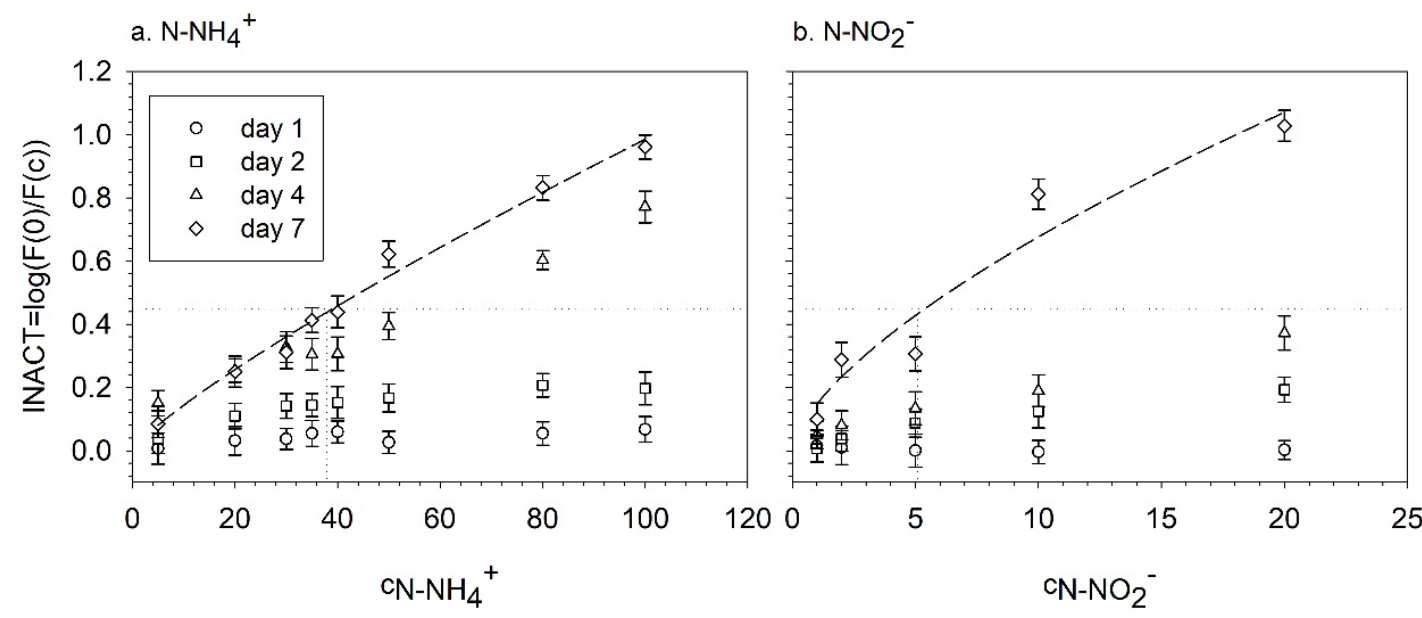

271 Figure 3. Inactivation INACT calculated from equation 1 versus the chemical dosage c (in

$272 \mathrm{ppm}$ ) and with exposure time (in days) for $\mathrm{N}^{-\mathrm{NH}_{4}}{ }^{+}(\mathrm{a})$ and $\mathrm{N}-\mathrm{NO}_{2}^{-}$(b). The dashed line

273 corresponds to the evolution on INACT with c after 7 days of exposure to $\mathrm{N}^{-\mathrm{NH}_{4}}{ }^{+}$and N-

$274 \mathrm{NO}_{2}-$. The dotted horizontal lines show the position of a $50 \%$ of inactivation (INACT 50 )

275 after 7 days of exposure to $\mathrm{N}^{-N_{4}}{ }^{+}$and $\mathrm{N}-\mathrm{NO}_{2}{ }^{-}$and the vertical dotted lines the 276 concentration of $\mathrm{N}-\mathrm{NH}_{4}{ }^{+}$and $\mathrm{N}-\mathrm{NO}_{2}{ }^{-}$at INACT 50.

277 The ratio between Daphnia swimming velocity for each chemical dosage $\mathrm{c}_{\mathrm{x}}\left(\right.$ for $\mathrm{x}=\mathrm{NH}_{4}{ }^{+}$,

$278 \mathrm{NO}_{2}^{-}, \mathrm{NO}_{3}^{-}$and $\left.\mathrm{PO}_{4}{ }^{3-}\right)$ and the swimming velocity for the control experiment without the 279 presence of chemicals $v_{D P h}\left(c_{x}\right) / v_{D p h}(0)$ was calculated (see Figure 4 for each chemical). $\mathrm{V}_{\mathrm{DPh}}\left(\mathrm{C}_{\mathrm{x}}\right) / \mathrm{V}_{\mathrm{Dph}}(0)$ decreased with the dosage and the time of exposure for both $\mathrm{NH}_{4}{ }^{+}$and

$281 \mathrm{NO}_{2}^{-}$(Figures $4 a$ and $b$, respectively). $\mathrm{V}_{\mathrm{DPh}}\left(\mathrm{c}_{\mathrm{x}}\right) / \mathrm{v}_{\mathrm{Dph}}(0)$ remained constant with the 
282 chemical dosage and exposure time for the tests with $\mathrm{NO}_{3}{ }^{-}$(Figure $4 \mathrm{c}$ ). For $\mathrm{PO}_{4}{ }^{3-}$, the 283 ratio $\mathrm{V}_{\mathrm{DPh}}\left(\mathrm{C}_{\mathrm{x}}\right) / \mathrm{V}_{\mathrm{Dph}}(0)$ showed a slight decrease for $\mathrm{CPO}^{3-}=30 \mathrm{mgN}^{3} \mathrm{NO}_{3}{ }^{-} \mathrm{L}^{-1}$, whereas for $284 \mathrm{CPO}_{4}{ }^{3-}>30 \mathrm{mgN}^{-N}{ }_{3}{ }^{-} \mathrm{L}^{-1}$ the decrease was greater, especially at exposure times after day 2854 (Figure 4d).

286 Daphnia mortality increased for all the $\mathrm{NH}_{4}{ }^{+}$dosages studied and with the exposure time 287 (Figure 5a). For the experiments carried out with $\mathrm{NO}_{2}{ }^{-}$, no mortality was observed for 288 the lowest $\mathrm{NO}_{2}{ }^{-}$dosage studied i.e., $1 \mathrm{mgN}^{-N_{2}}{ }_{2}^{-} \mathrm{L}^{-1}$ (Figure 5b). For $\mathrm{NO}_{2}{ }^{-}$dosages above 2892 mgN-NO${ }_{2}^{-} \mathrm{L}^{-1}$, mortality increased gradually with the $\mathrm{NO}_{2}^{-}$dosage and with the 290 exposure time. Greater mortality rates were obtained for the highest dosages tested 291 with $\mathrm{NH}_{4}{ }^{+}$than for those tested with $\mathrm{NO}_{2}{ }^{-}$(Figures $5 \mathrm{a}$ and $5 \mathrm{~b}$, respectively). No mortality 292 was observed for the case of the $\mathrm{NO}_{3}{ }^{-}$and $\mathrm{PO}_{4}{ }^{3-}$ chemicals, neither in terms of chemical 293 dosage nor exposure time (data not shown). 


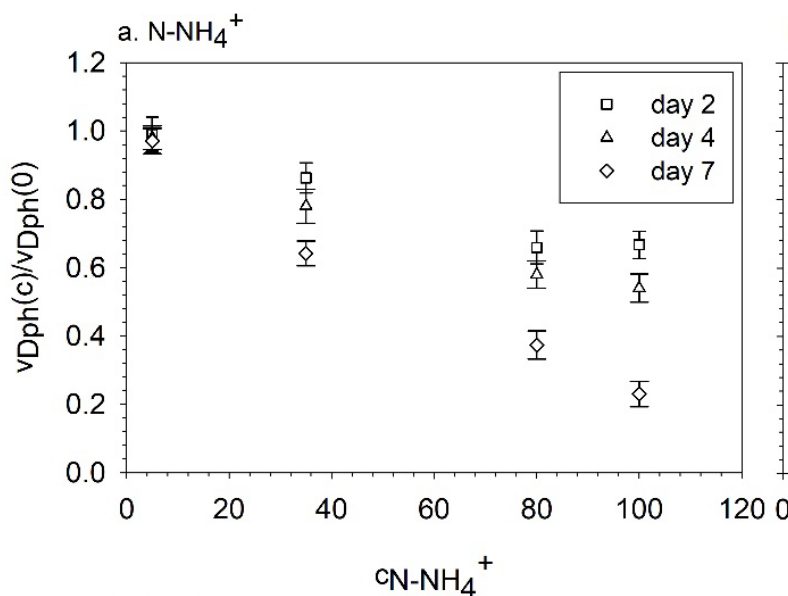

b. $\mathrm{N}-\mathrm{NO}_{2}{ }^{-}$
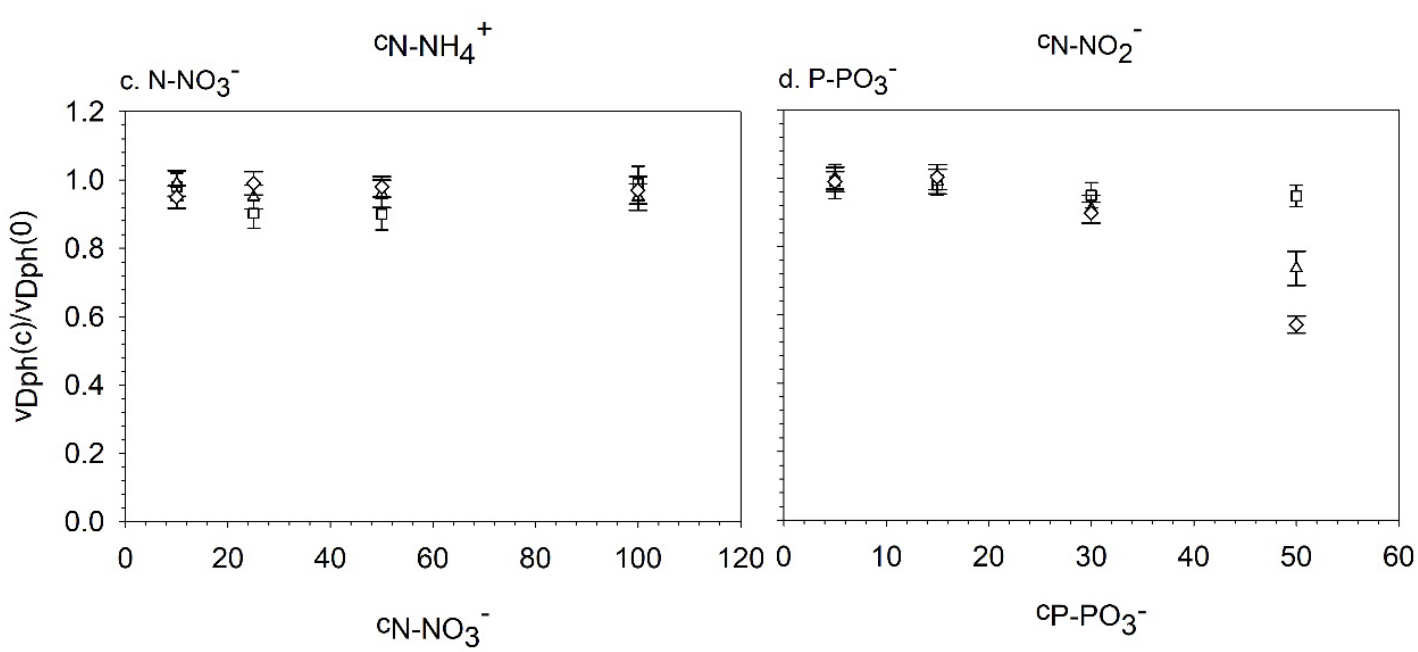

294

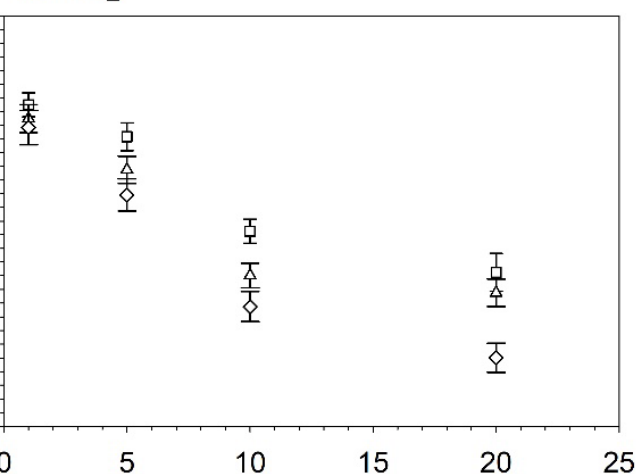

295 Figure 4. Ratio $v_{D P h}(c) / v_{D P h}(0)$ versus the chemical dosage $c$ and with exposure time for $\mathrm{N}-\mathrm{NH}_{4}^{-}$(a) and $\mathrm{N}-\mathrm{NO}_{2}^{-}$(b), N-NO${ }_{3}^{-}$(c) and $\mathrm{P}-\mathrm{PO}_{4}{ }^{3-}$ (d).

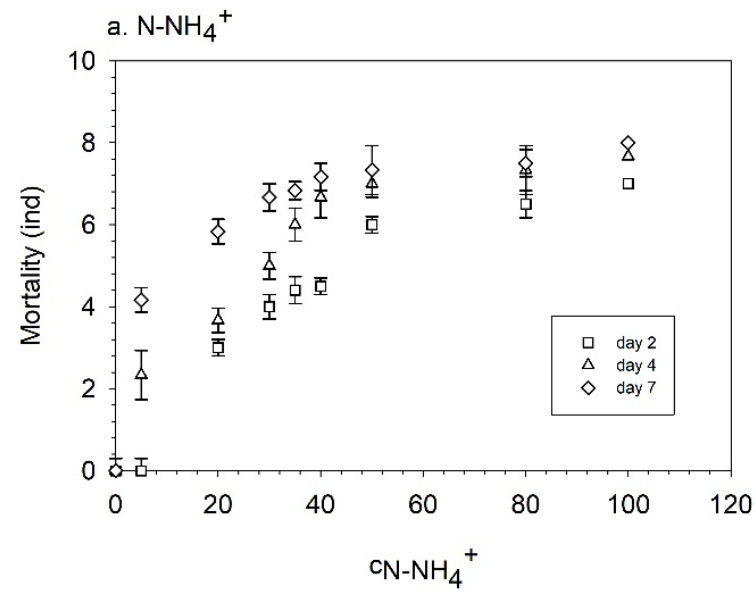

b. $\mathrm{N}-\mathrm{NO}_{2}{ }^{-}$

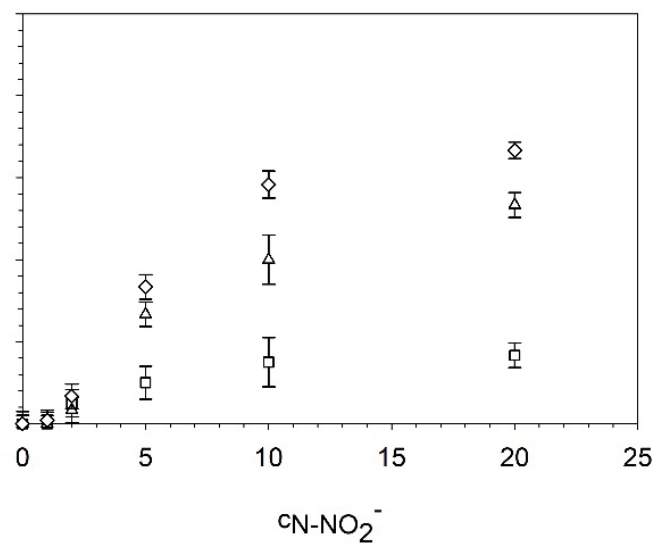


298 Figure 5. Mortality versus the chemical dosage $\mathrm{c}$ (in ppm) for different exposure times 299 (in days) for $\mathrm{N}^{-\mathrm{NH}_{4}^{-}}{ }^{-}$(a) and $\mathrm{N}-\mathrm{NO}_{2}^{-}$(b).

\section{Discussion}

301 By exposing Daphnia magna to the presence of chemicals commonly found in 302 wastewater treatment plants $\left(\mathrm{NH}_{4}{ }^{+}, \mathrm{NO}_{2}{ }^{-}, \mathrm{NO}_{3}{ }^{-}\right.$and $\left.\mathrm{PO}_{4}{ }^{3-}\right)$, their filtering capacity, 303 swimming velocity and their mortality rates have been found to be differentially 304 affected.

305 The continued exposure of Daphnia to ammonium and nitrite increased the inactivation 306 of Daphnia filtration. After one day of exposure the inactivation in Daphnia filtration 307 was minimal, but this increased with the exposure time to ammonium and nitrite. That 308 is, levels of ammonium above $35 \mathrm{mgN}^{-N_{4}}{ }_{4}{ }^{-1} \mathrm{~L}^{-1}$ inhibited Daphnia filtration by 0.4 after 7 days of exposure, i.e., an $80 \%$ reduction in Daphnia filtration compared to the case

310 without the presence of $\mathrm{NH}_{4}{ }^{+}$. Although there are no studies reporting the effect of 311 Daphnia inhibition due to the presence of ammonium $\left(\mathrm{NH}_{4}{ }^{+}\right)$, there are some that 312 present Daphnia filtering inhibition due to the presence of ammonia $\left(\mathrm{NH}_{3}\right)$. The concentration of ammonia at a certain ammonium concentration was calculated

314 following the methodology explained by Anthonisen et al. (1976). In our study, the concentration of $35 \mathrm{mgN}-\mathrm{NH}_{4}{ }^{+} \mathrm{L}^{-1}$ at $\mathrm{pH}=7.5$ and a temperature of $20{ }^{\circ} \mathrm{C}$ represents the presence of ammonia $\left(\mathrm{N}-\mathrm{NH}_{3}\right)$ with a concentration of $0.3 \mathrm{mgN}-\mathrm{NH}_{3} \mathrm{~L}^{-1}$. In this case, the results for Daphnia inhibition are similar to those of Norgaard and Roslev (2016) who

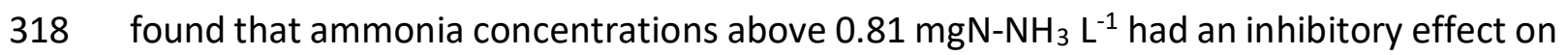
319 the E.coli removal by Daphnia. From Norgard and Roslev (2016) work, such ammonia concentrations produced a $70 \%$ inhibitory effect on the Daphnia filtering rate, which is 
321 close to the $80 \%$ found in this present study. Furthermore, in the present study, Daphnia

322 mortality for $\mathrm{N}-\mathrm{NH}_{4}{ }^{+}$above $35 \mathrm{mgN}-\mathrm{NH}_{4}{ }^{+} \mathrm{L}^{-1}$ and after 7 days of exposure increased up

323 to $14 \%$ and swimming velocities $50 \%$ below those for Daphnia individuals not exposed

324 to $\mathrm{N}-\mathrm{NH}_{4}{ }^{+}$. Whether the inhibition of Daphnia is caused by ammonium or ammonia ionic

325 form would require further studies at different $\mathrm{pHs}$ and a molecular level. In addition,

326 the crimson color of those Daphnia individuals under high ammonium and high nitrite

327 concentrations faded with time and reaching a white/transparent color at the end of

328 the experiment. The change in their color can be attributed to the impossibility to

329 synthetize haemoglobin, suggesting the malfunctioning of important physiological

330 functions (Seidl et al., 2005). Nevertheless, from the engineering point of view the

331 concentration of $35 \mathrm{mgN}-\mathrm{NH}_{4}{ }^{+} \mathrm{L}^{-1}$ at a neutral $\mathrm{pH}(7.5)$ would mean a warning signal for

332 Daphnia reactor operation. The Daphnia magna inactivation above a 50\% (INACT 50 )

333 after 7 days of exposure to $\mathrm{NH}_{4}{ }^{+}$and $\mathrm{NO}_{2}{ }^{-}$can be calculated (Figures $4 \mathrm{a}$ and $4 \mathrm{~b}$ ). INACT ${ }_{50}$

334 was reached after 7 days of exposure to concentrations of $\mathrm{N}-\mathrm{NH}_{4}{ }^{+}$above $40 \mathrm{ppm}$ and N-

$335 \mathrm{NO}_{2}^{-}$above $5 \mathrm{ppm}$.

336 The presence of nitrite above $5 \mathrm{mgN}^{-N_{2}}{ }_{2}^{-} \mathrm{L}^{-1}$ reduced the filtering rate of Daphnia after

3377 days to $c / c_{0}=0.51$, representing a $13 \%$ reduction compared with the case without the

338 presence of nitrite. In such conditions, mortality after 7 days of exposure was $6 \%$. This

339 mortality coincides with the $7 \%$ found by Xiang et al., (2011) for Daphnia after an

340 exposure of $\mathrm{N}^{-\mathrm{NO}_{2}}{ }^{-}$for 21 days in the same nitrite concentrations. In addition, for

341 Daphnia exposed to $\mathrm{N}-\mathrm{NO}_{2}{ }^{-}$concentrations of $5 \mathrm{mgN}-\mathrm{NO}_{2}{ }^{-} \mathrm{L}^{-1}$ and with exposure times

342 of 7 days, swimming velocities were reduced by $30 \%$ compared to those found for

343 Daphnia non-exposed to the $\mathrm{N}^{-N_{2}}{ }^{-}$chemical. This percentage is lower than the 
percentage in Daphnia mortality for the same experiments (with a maximum of a $16 \%$

345 after 7 days of exposure). This result indicates that the presence of the chemical affects

346 Daphnia and that longer exposure times above 7 days might produce greater 347 mortalities.

348 Daphnia exposed to the range of nitrate concentrations $\left(\mathrm{N}-\mathrm{NO}_{3}{ }^{-}\right)$tested were not found

349 to present greater mortality or lower filtering rates than those for the non-exposed

350 Daphnia. In addition, their swimming velocity also remained unaltered. Daphnia filtering

351 and mortality rates were also unaltered when exposed to phosphate concentrations in

352 the range from $0-50$ mgP- $\mathrm{PO}_{4}{ }^{3-} \mathrm{L}^{-1}$ and compared with the non-exposed Daphnia.

353 However, their swimming velocity for $\mathrm{P}_{-} \mathrm{PO}_{4}{ }^{3-}$ concentrations of $50 \mathrm{mgP}-\mathrm{PO}_{4}{ }^{3-} \mathrm{L}^{-1}$ after 7

354 days of exposure, decreased by $40 \%$ compared to that of the non-exposed Daphnia.

355 Currier and Elser (2017) exposed Daphnia to high $\mathrm{PO}_{4}{ }^{3-}$ and found that after a period of

356 one month the Daphnia exposed to high phosphate concentrations had lower growth

357 and feeding rates than those found for Daphnia exposed to low $\mathrm{PO}_{4}{ }^{3-}$-concentrations or

358 those not exposed to $\mathrm{PO}_{4}{ }^{3-}$.

359 Therefore, in the present study, the swimming velocity seems to be the most sensitive

360 parameter and clearly makes the effect high phosphate concentrations have on Daphnia

361 evident. This result is in accordance with Bownik (2017) who stated that Daphnia

362 mobility is a sensitive biomarker affected by various substances. Longer exposure times

363 at these $\mathrm{PO}_{4}{ }^{3-}$ concentrations are expected to deviate from those for non-exposed

364 Daphnia. 
366 Therefore, the use of a tertiary based technology based on Daphnia magna

367 zooremediation might not produce satisfactory results for effluents rich in ammonium

368 or nitrites ( $>35 \mathrm{mgN}-\mathrm{NH}_{4}{ }^{+} \mathrm{L}^{-1}$ and $>5 \mathrm{mgN}^{-N_{2}}{ }_{2}^{-} \mathrm{L}^{-1}$, respectively) when they are exposed

369 to such contaminants for periods longer than 1 day. However, treated wastewater from

370 a secondary wastewater treatment plant might not have such elevated concentrations

371 of ammonium and nitrite and, in this case the performance of a treatment based on

372 Daphnia would not be expected to alter. Therefore, the use of Daphnia as a tertiary

373 treatment can be suitable provided the levels of the $\mathrm{N}-\mathrm{NH}_{4}{ }^{+}$and $\mathrm{N}-\mathrm{NO}_{2}^{-}$remain below

37435 and $5 \mathrm{mg} \mathrm{L}^{-1}$, respectively. In addition, short temporal exposures of one day to these

375 contaminants might be overcome by the Daphnia population. Nitrate was not found to

376 produce changes in Daphnia behaviour over the range of nitrate concentrations studied

377 or during the exposure time considered. Phosphate did not produce any change in

378 Daphnia mortality or their filtering rates either. However, the longest exposure time

379 studied at the highest phosphate concentrations was found to produce a decrease in

380 Daphnia swimming velocities. This indicates that longer exposure times to such

381 conditions might cause changes in Daphnia behaviour. Therefore, a natural-based

382 tertiary treatment based on Daphnia could be used based on their activity behaviour

383 under the expected chemical composition range.

384 This study presents an evaluation of the Daphnia filtration, swimming and mortality

385 under ammonium, nitrite, nitrate and phosphate separately. The effect of the

386 combination of these chemicals and other compounds typical from wastewater

387 treatment plants remains still unknown and can be the aim of a future study.

\section{Acknowledgements}


389

390

391

392

393

394

395

396

397

398

399

400

401

402

403

404

405

406

407

408

409

410

411

This work was supported by the University of Girona funding MPCUdG2016 and by the INNOQUA project from the European Union's Horizon 2020 research and innovation program (Ares(2016)1770486).

\section{References}

Ait-Mouheb, N., Bahri, A., Thayer, B.B., Benhyahia, B., Bourrié, G., Cherki, B., Condom, N., Declercq, R., Gunes, A., Héran, M., Kitir, N., Molle, B., Patureau, D., Pollice, A., Rapaport, A., Renault, P., Riahi, K., Romagny, B., Sari, T., Sinfort, C., Steyer, J.-P., Talozi, S., Topcuoglu, B., Turan, M., Wéry, N., Yildirim, E., Harmand, J., 2018. The reuse of reclaimed water for irrigation around the Mediterranean Rim: a step towards a more virtuous cycle? Reg. Environ. Chang. 18, 693-705.

Anthonisen, A.C., Loher, R.C., Prakasam, T.B.S., Srinath, E.G., 1976. Inhibition of nitrification by ammonia and notrous acid. J. Water Pollut. Control Fed. 48, 835852.

Arruda, J.A., Marzolf, G.R., Flauk, R.T., 1983. The role of suspended sediments in the nutrition of zooplankton in turbid reservoirs. Ecology 64, 1225-1235.

Bouzit, M., Das, S., Cary, L., 2016. Valuing treated wastewater and reuse: preliminary implications from a meta-analysis. Water Econ. Policy 3, 1650044.

Bownik, A., 2017. Daphnia swimming behaviour as a biomarker in toxicity assessment: A review. Sci. Total Environ. 601-602, 1-1868.

Burnet, J., Faraj, T., Cauchie, H., Joaquim-Justo, C., Servais, P., Prévost, M., Dorner, S.M., 2017. How does the cladoceran Daphnia pulex affect the fate of Escherichia coli in water ? PLoS One 1-16. https://doi.org/10.1371/journal.pone.0171705

C.M., C., Elser, J.J., 2017. Beyond monoculture stochiometry studies: assessing growth, 
Gliwicz, Z.M., 1990. Food thresholds and body size in Cladocerans. Nature 343, 638640.

Heger, S., Du, M., Bauer, K., Schäffer, A., Hollert, H., 2018. Comparative ecotoxicology of potential biofuels to water flea (Daphnia magna), zebrafish (Danio rerio) and Chinese hamster (Cricetulus griseus) V79 cells. Sci. Total Environ. 631-632, 216222.

Jaramillo, M.F., Restrepo, I., 2017. Wastewater reuse in agriculture: a review about its limitations and benefits. Sustainability 9, 1734.

Jensen, F.B., 2003. Nitrite disrupts multiple physiological functions in aquatic animals. Comp. Biochem. Physiol. Part A. 135, 9-24.

424

Lari, E., Steinkey, D., Pyle, G.G., 2017. A novel apparaturs for evaluating contaminant effects on feeding activity and heart rate in Daphnia spp. Ecotoxicol. Environ. Saf.

Maceda-Veiga, A., Webster, G., Canals, O., Salvadó, H., Weightman, A.J., Cable, J., 2015. Chronic effects of temperature and nitrate pollution on Daphnia magna: Is this cladoceran suitable for widespread use as a tertiary treatment? Water Res. 83, 141-152.

Matamoros, V., Sala, L., Salvadó, V., 2012. Evaluation of a biologically-based filtration water reclamation plant for removing emerging contaminants: A pilot plant study. Bioresour. Technol. 104, 243-249. engineering. Treatment and reuse. McGraw-Hill. 
Moison, M., Schmitt, F.C., Souissi, S., 2012. Effect of Temperature on Temora longicornis swimming behaviour: Illustration of seasonal effects in a temperate ecosystem. Aquat. Biol. 16, 149-162.

Norgaard, L.S., Roslev, P., 2016. Effects of ammonia and density on filtering of commensal and pathogenic escherichia coli by the cladoceran Daphnia magna. Bull. Environ. Contam. Toxicol. 97, 848-854.

Pan, Y., Yan, S.-W., Li, R.-Z., Hu, Y.-W., Chang, X.-X., 2017. Lethal/sublethal responses of Daphnia magna to acute norfloxacin contamination and changes in phytoplankton-zooplankton interactions induced by this antibiotic. Sci. Rep. 7, 40385.

Paredes, L., Alfonsin, C., Allegue, T., Omil, F., Carballa, M., 2018. Integrating granular activated carbon in the post-treatment of membrane and settler effluents to improve organic micropollutants removal. Chem. Eng. J. 345, 79-86.

Pau, C., Serra, T., Colomer, J., Casamitjana, X., Sala, L., Kampf, R., 2013. Filtering capacity of Daphnia magna on sludge particles in treated wastewater. Water Res. $47,181-186$.

Praveen, P., Guo, Y., Kang, H., Lefebvre, C., Loh, K.C., 2018. Enhancing microalgae cultivation in anaerobic digestate through nitrification. Chem. Eng. J. 354, 905912. https://doi.org/10.1016/j.cej.2018.08.099

Seidl, M.D., Pirow, R., Paul, R.J., 2005. Acclimation of the microcrustacean Daphnia magna to warm temperatures is dependent on haemoglobin expression. J. Therm. Biol. 30, 532-544. https://doi.org/10.1016/j.jtherbio.2005.06.004

Serra, T., Barcelona, A., Soler, M., Colomer, J., 2018. Daphnia magna filtration efficiency and mobility in laminar to turbulent flows. Sci. Total Environ. 621, 626- 
461

462

463

464

465

466

467

468

469

470

471

472

473

474

475

476

477

478

479

480

481

482

483

Serra, T., Colomer, J., 2016. The hydraulic retention time on the particle removal efficiency by Daphnia magna filtration on treated wastewater. Int. J. Environ. Sci. Technol. 13, 1433-1442.

Serra, T., Colomer, J., Cristina, X., Vila, X., Arellano, J.B., Casamitjana, X., 2001.

Evaluation of a laser in situ scattering instrument for measuring the concentration of phytoplankton, purple sulphur bacteria and suspended inorganic sediments in lakes. J. Environ. Eng. 127, 1023-1030.

Serra, T., Colomer, J., Gacia, E., Soler, M., Casamitjana, X., 2002a. Effects of a turbid hydrothermal plume on the sedimentation rates in a karstic lake. Geophys. Res. Lett. 29, 1-5.

Serra, T., Colomer, J., Pau, C., Marín, M., Sala, L., 2014. Tertiary treatment for wastewater reuse based on the Daphnia magna filtration - Comparison with conventional tertiary treatments. Water Sci. Technol. 70, 705-710.

Serra, T., Colomer, J., Zamora, L., Moreno-Amich, R., Casamitjana, X., 2002b. Seasonal development of a turbid hydrothermal lake plume and the effects on the fish distribution. Water Res. 36, 2753-2760.

Shiny, K., Remani, K., Nirmala, E., Jalaja, T., Sasidharan, V., 2005. Biotreatment of wastewater using aquatic invertebrates, Daphnia magna and Paramecium caudatum. Bioresour. Technol. 96, 55-58.

Sladkova, S.V., Kholodkevich, S.V., Olsen, G.H., Geraudie, P., Camus, L., 2016. Acute and long-term effects of sucralose on the water flea Daphnia magna on mobility, survival and reproduction at different temperature regimes. Chem. Ecol. 32, 952960. 
Van de Perre, D., Janssen, C.R., De Schamphelaere, K.A.C., 2018. Combined effects of interspecies interaction, temperature, and zinc on Daphnia longispina population dynamics. Environ. Toxicol. Chem. 37, 1668-1678.

487 Wickramarathna, L.N., Noss, C., Lorke, A., 2014. Hydrodynamic trails produced by 488 Daphnia: size and energetics. PLoS One 9, e92383.

489

Xiang, F., Geng, L., Lü, K., Zhang, J., Minter, E.J.A., Yang, Z., 2012. Effect of long-term

490 nitrite exposure on the cladoceran Daphnia obtusa: Survival, moults, and

491 reproduction. Biochem. Syst. Ecol. 41, 98-103.

492

Xiang, F., Yang, W., Chen, Y., Zhou, Y., 2011. Acute toxicity of nitrite and ammonia to Daphnia similoides of different developmental stages: Using the modified

494 Gaussian model to describe. Bull. Environ. Contam. Toxicol. 84, 708-711.

495

496

497 
499 The temporal evolution of the spirulina concentration decreases through a first order

500 equation with time and with a constant $k$ as:

501

$$
\frac{d c}{d t}=-k t
$$

502

that has an exponential as a solution for the temporal evolution of the concentration as

503 follows (Pau et al., 2013):

504

$$
\frac{c}{c_{0}}=e^{-k t}
$$

505 where $\mathrm{k}$ is the rate of particle removal by both sedimentation $\left(\mathrm{k}_{\mathrm{s}}\right)$ and Daphnia filtration $506\left(k_{\text {Dph }}\right)$, i.e., $k=k_{s}+k_{D p h}$.

507 From Equation (2) k can be solved following

508

$$
k=-\frac{1}{t} \ln \left(\frac{c}{c_{0}}\right)
$$

509 and $\mathrm{k}_{\mathrm{s}}$ can be determined from those experiments without Daphnia (in which $\mathrm{k}_{\mathrm{Dph}}=0$ ).

510 Therefore, $\mathrm{k}_{\mathrm{Dph}}$ will be calculated for the rest of the experiments with Daphnia. The rate

511 of decrease of c due to Daphnia filtration, is a function of the filtering rate of each

512 Daphnia individual $\left(\mathrm{F}\right.$, in $\left.\mathrm{mL}^{\text {ind }} \mathrm{d}^{-1} \mathrm{~L}^{-1}\right)$ and the Daphnia concentration in such a way that

513 (Pau et al., 2013),

$$
k_{D p h}=F\left(c_{x}\right) \times C_{D p h}
$$

516 With chemicals, the decay in the suspended particle concentration is expected to be 
517 modified with respect to that found for the 'without chemicals', and follows,

518

$$
\frac{d c}{d t}=-k_{\text {Chem }} t
$$

519 where $k_{\text {chem }}$ is the total decay constant due to the presence of chemicals,

520

$$
\mathrm{k}_{\mathrm{Chem}}=\mathrm{k}_{\mathrm{s}}+\mathrm{k}_{\mathrm{Dph}}^{\prime}
$$

521 and

522

$$
k^{\prime}{ }_{D p h}=k_{D p h}-k^{\prime}
$$

523 where $k^{\prime}$ is the modification to the Daphnia filtration decay constant due to the presence

524 of chemicals.

525 Equation (5) can be solved and results in,

526

$$
\left(\frac{c}{c_{0}}\right)_{\text {with chemical }}=e^{-k_{\text {Chem }} t}
$$

527 and therefore,

$$
k_{\text {Chem }}=-\frac{1}{t} \ln \left(\frac{c}{c_{0}}\right)_{\text {with chemical }}
$$

529 Using equations (6) and (9), $\mathrm{k}_{\mathrm{Dph}}^{\prime}$ can be obtained and then the filtration in the 530 presence of chemicals $\left(F\left(c_{x}\right)\right)$ can be calculated,

$$
k^{\prime}{ }_{D p h}=F\left(c_{x}\right) \times C_{D p h}
$$

532 The ratio between equation (8) and equation (2) can be calculated following, 
535 